\title{
The Situation of Liver Transplantation Programs in Iran
}

\author{
Kamran B Lankarani ${ }^{1, *}$, Seyed Ali Malek Hosseini ${ }^{2}$
}

1. Health Policy Research Center. Insti-

Please cite this paper as:

B Lankarani K, Malek Hosseinin SA. The Situation of Liver Transplantation Programs in tute of Health, Shiraz University of Medical Sciences, Islamic Republic of Iran

2. Shiraz Transplant Research Center, Shiraz University of Medical Sciences, Shiraz, Islamic Republic of Iran

\footnotetext{
* Corresponding Author:

Kamran B. Lankarani, M.D

Health Policy Research Center, Institute of Health, $8^{\text {th }}$ Floor, Building No. 2, School of Medicine, Zand Avenue, Shiraz, IR Iran Telefax: + 987132309615

Email: lankaran@sums.ac.ir

Received: 02 May 2018

Accepted: 25 Jun. 2018
}

We read with interest the article by Saidi and colleagues on current challenges of liver transplantation (LT) in Iran. ${ }^{1}$ The authors have truly pointed out the increasing need for LT in Iran, but some of the issues they raised as challenges need to be looked more carefully.

The authors claimed that there was no national registry for LT in Iran. Indeed Ministry of Health and Medical Education of Iran (MOHME) has an active registration system in place for all transplanted patients including solid organ transplantation recipients for more than two decades. Despite gradual but progressive improvement of this system, there is still space for improvements. Recently this system has been linked to drug providing system, which further facilitates providing the subsidized immunosuppressive drugs to these patients.

There is a need for more proactive role of MOHME specially in strengthening the national organ procurement and transplantation registry and in supervising transplantation centers. Part of this weakness is related to the weakness in expertise in the Ministry. It was one of the rare occasions that an innovative program was more developed in the periphery of the country rather than in the capital Tehran. This has led to some ignorance and even misunderstanding on what should be done considering the realities of LT in a wide nation in a country with an area of more than 1,600,000 square Kilometers. Recent reestablishment of the Supreme Council of Transplantation in MOHME could be a progress in this regard.

As we mentioned previously the start of LT program in Iran was based on historical fatwa of late Imam Khomeini on May 21, 1989, which was further underscored by his successor Imam Khamenei. ${ }^{2}$ The law passed by Iranian parliament on brain death, which was based on these fatwas, was indeed the first among Islamic countries and to the best of our knowledge there are no such law in many Islamic countries, which makes Iran and the Shiite's Jurisprudence the pioneer in providing the opportunity for expansion of the solid organ transplantation among Islamic countries. Most of these countries still rely heavily on living donation. ${ }^{3}$ The importance of this momentum should not be forgotten. The fatwa and the act give the MOHME the power to further regulate the transplantation programs and promote coordination among them. 
There has been growing cooperation among centers. For instance in Shiraz we have received many livers from other centers including Tehran but there is much to do especially in a systematic manner for cooperation rather than competition between centers especially those in the capital.

We agree with the authors on the importance of public awareness and we believe this is something that should be more done by civil societies and non-governmental organizations while the government should provide the framework for such activities. For instance the provision of opportunity to announce legally acceptable willing to donate and facilitation of this issue still needs legislations. As was mentioned by the authors, only about one third of confirmed brain-death victims whose legal guardians have declared willing to donate organs proceeded to real donation. Part of this might be explained by poor conservation of organs as was noticed by the authors but to the best our knowledge the most important issue is weakness of organ transplantation centers to recall recipients on a timely manner and be ready for urgent operations. Some of the centers in the country work with one to at most three transplantation surgeons, which makes on the clock and 7 days per week service provision unmanageable. In Shiraz the rate of not using an organ because of these logistic problems is near zero. Using all of possibilities and through hard devoted working of all of the team members, the total number of liver transplantations in Shiraz reached 638 in 2017, which is the highest record of LT in a single center ever chronicled in transplantation history.

We agree with the authors on the necessity to expand LT programs in Iran but these centers should be stable and prosperous centers not being temporary demonstrations. There is a need for devoted professionals whose main work is LT to achieve this goal. Such people, not the instruments or buildings, are the most important assets of any program. These people could continue to develop the needed infrastructure, educate others, have plan for continuous professional development, get the support from stakeholders and charities, and raise funds among other activities. Successful and/or failed programs in Iran should be best analyzed considering these issues.

Regarding the cost of LT, it should be mentioned that the program is fully supported by the government subsidies since 2005, which has resulted in decreased disparities on the use of this life saving treatment as we reported several years ago. ${ }^{4}$ The major problem now is for the postoperative long term care in which the extent of coverage by insurance companies needs to be improved. Furthermore there is a misconception among some recipients on the way they should go back to work. This has improved and now many of our patients are back to work and are now financially productive so that they can provide the costs of their families and their own long term care.

In summary much has been achieved in LT in Iran since its launch in a quarter of century ago but still there is much to do. The main point is the cooperation between experts and looking to these issues through equity lens and with strict professional ethics.

\section{ETHICAL APPROVAL}

There is nothing to be declared.

\section{CONFLICT OF INTEREST}

The authors declare no conflict of interest related to this work.

\section{REFERENCES}

1. Saidi RF, Kazemaini SM, Malekzadeh R. Current Challenges of Liver Transplantation in Iran. Middle East J Dig Dis 2018;10:45-9. doi: 10.15171/mejdd.2017.90.

2. Malek Hosseini SA, Nikeghbalian S, Salahi H, Kazemi K, Shemsaeifar A, Bahador A, et al. Evolution of Liver Transplantation Program in Shiraz, Iran. Hepat Mon 2017;17:e60745. doi: 10.5812/hepatmon.60745.

3. Amer KE, Marwan I. Living donor liver transplantation in Egypt. Hepatobiliary Surg Nutr 2016;5:98-106. doi: 10.3978/j.issn.2304-3881.2015.10.03.

4. Lankarani KB, Mahmoodi M, Gholami S, Mehravar S, Malekhosseini SA, Heydari ST, et al. Reducing Social Disparity in Liver Transplantation Utilization through Governmental Financial Support. Hepat Mon 2012;12:e6463. doi: 10.5812/hepatmon.6463. 